\title{
Ultrafiltration Behaviour of Trihalomethanes (THMs) from Petrochemical Wastewater
}

\author{
Indok Nurul Hasyimah Mohd. Amin* and Nur Fatihah Hakema Ishak \\ Department of Chemical and Bioengineering Technology (Process), \\ Universiti Kuala Lumpur Malaysian Institute of Chemical and Bioengineering \\ Technology (UniKL-MICET), Lot 1988, Kawasan Perindustrian Bandar Vendor, \\ Taboh Naning, 78000 Alor Gajah, Melaka, Malaysia \\ "Corresponding author: nurulhasyimah@unikl.edu.my
}

Published online: 25 October 2018

To cite this article: Mohd. Amin, I. N. H. \& Ishak, N. F. H. (2018). Ultrafiltration behaviour of trihalomethanes (THMs) from petrochemical wastewater. J. Phys. Sci., 29(Supp. 3), 55-62, https://doi.org/10.21315/jps2018.29.s3.7

To link to this article: https://doi.org/10.21315/jps2018.29.s3.7

\begin{abstract}
This work investigated the ultrafiltration of trihalomethanes (THMs) from petrochemical wastewater by polyethersulfone (PES) membrane. The ultrafiltration process was carried out by using UHP-62 dead-end filter cell unit. The wastewater was initially characterised using Fourier transform infrared (FTIR) and gas chromatography $(G C)$ to identify the presence and concentrations of THMs, respectively. Prior to the experiment, PES membrane was soaked overnight with deionised water before being used to remove the particles attached on the membrane surface during their packaging and transportation. The concentration of THMs in the feed was determined and the effects of solution chemistry were studied to investigate the removal efficiency of the THMs by PES membranes. The operating pressure was kept constant at 1 bar and the homogeneity of the feed solution was achieved with a constant stirring at $400 \mathrm{rpm}$. FTIR was used to analyse the THM removal through IR spectrum result. The study showed that the effect of pH somehow gave significantly acceptable results on the THM removal. The chloroform functional group was found at peak $771.71 \mathrm{~cm}^{-1}$ with highest concentration about $1750 \mu \mathrm{gl}^{-1}$. At neutral and alkaline conditions, no chloroform peak was detected, whereas in acidic solution, the peak was identified at $717.22 \mathrm{~cm}^{-1}$.
\end{abstract}

Keywords: Ultrafiltration, polyethersulfone membranes, petrochemical wastewater, trihalomethanes, PES membrane 


\section{INTRODUCTION}

The most common trihalomethane (THM) compounds formed from chlorination are dibromochloromethane $\left(\mathrm{CHClBr}_{2}\right)$, bromoform $\left(\mathrm{CHBr}_{3}\right)$, chloroform $\left(\mathrm{CHCl}_{3}\right)$ and dichlorobromomethane $\left(\mathrm{CHCl}_{2} \mathrm{Br}\right) .{ }^{1}$ Among them, $\mathrm{CHCl}_{3}$ has the highest concentration. Chlorination is one of the common treatments used widely in the industrial sector to attain bacteriological quality and produce safe water due to its efficiency, stability and cost effectiveness. ${ }^{2-4}$ Chlorinated water develops a certain flavour and smell found in tap water which sometimes become a cause for complaint. ${ }^{2-7}$ Several studies reported the existence of disinfection by-products (DBPs) caused by chlorination of organic matters presence in the fresh water, especially THMs, which may adversely affect human health. The Environmental Protection Agency (EPA) has established that THMs have been linked to cancerrelated diseases, and may result in reproductive problems, miscarriage and other potential harms.

In industries, water is used for numerous applications such as cooling water, rinsing and chemical productions, solvents, boiler feed, purified water, injection liquid as well as for equipment cleaning purpose. However, water quality must be controlled to avoid corrosion, equipment damage and any blockage in the pipeline due to water precipitation. THMs exhibit mutagenous and carcinogenic properties, and due to these properties, their presence in water might become physiological hazards. ${ }^{5}$ Conventional water treatment plant consists of physical treatment method that includes screening, sedimentation, floatation and filtration processes. On the other hand, chemical treatment involves $\mathrm{pH}$ adjustment, coagulation-fluctuation, oxidation-reduction and adsorption processes. ${ }^{6}$ These are some methods commonly used but they vary depending on the types of wastewater for the treatment. Hence, the aim of this work is to remove THM contents in petrochemical by ultrafiltration. The influence of solution chemistry was investigated throughout the experiment to determine the effectiveness of the filtration process.

\section{EXPERIMENTAL}

A 4-1 feed wastewater sample was supplied by a local petrochemical company, Petronas Penapisan (Melaka) Sdn. Bhd., Malaysia. The $\mathrm{pH}$ of the sample was measured at 1.91 and the physical appearance was light clear-blue colour (Figure 1). The characteristic was adjusted with sodium chloride $(\mathrm{NaOH})$ and hydrochloric acid $(\mathrm{HCl})$. 


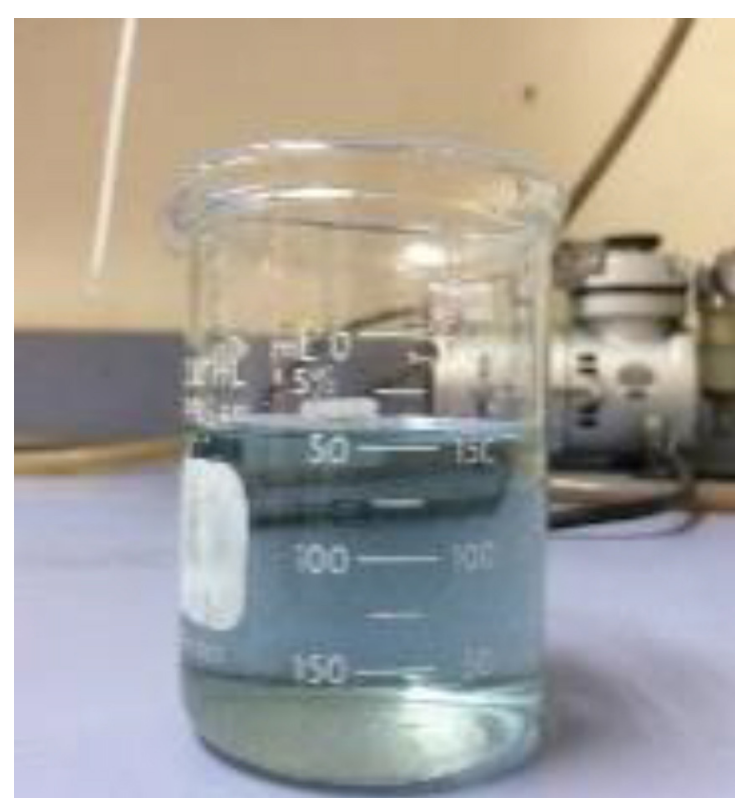

Figure 1: Physical appearance of the feed solution.

\subsection{Experimental Methods}

Initially, the sample was characterised by using gas chromatography (GC) and Fourier-transform infrared (FTIR) to determine the concentration and presence of THMs. An amount of $200 \mathrm{ml}$ of feed water sample was filled in the dead-end filter unit and pressurised with nitrogen gas. The allowable pressure was 1 bar and stirring speed at $400 \mathrm{rpm}$ to promote solution homogeneity. ${ }^{2}$ The permeate flux was collected in $50 \mathrm{ml}$ of beaker for $60 \mathrm{~min}$. Then, it was analysed to determine the THM removal. The characteristic of the feed sample was adjusted to different $\mathrm{pH}$ values of 4,7 and 10 .

\section{RESULTS AND DISCUSSION}

\subsection{Determination of THMs in the Feed Sample}

Figure 2 represents the functional group of THMs in the feed solution. It was found that the functional group of alkyl halides appears at wavenumber $719.88 \mathrm{~cm}^{-1}$ while the functional group of chloroform which is associated with C-Cl bond was found at $700-785 \mathrm{~cm}^{-1}$ region. According to Environmental Fact Sheet of New Hampshire Department, US, THMs were found in highest concentration 
as chloroform. ${ }^{3}$ Alkyl halides are compounds in which $\mathrm{C}$ is attached to $\mathrm{X}$, where $\mathrm{X}$ may indicate any halogen or combination of halogens atom. ${ }^{4}$ Another functional group of THMs which corresponds to $\mathrm{C}=\mathrm{C}$ bonding appears at $1620-1680 \mathrm{~cm}^{-1}$.

Figure 3 shows the concentration of THMs in the petrochemicals wastewater. It was recorded that the concentration of chloroform is the highest at $1750 \mu \mathrm{g}^{-1}$, while the concentrations for bromoform, dichloromethane and bromodichloromethane vary between $70 \mu \mathrm{g} \mathrm{1^{-1 }}$ and $200 \mu \mathrm{g} \mathrm{1^{-1 }}$.

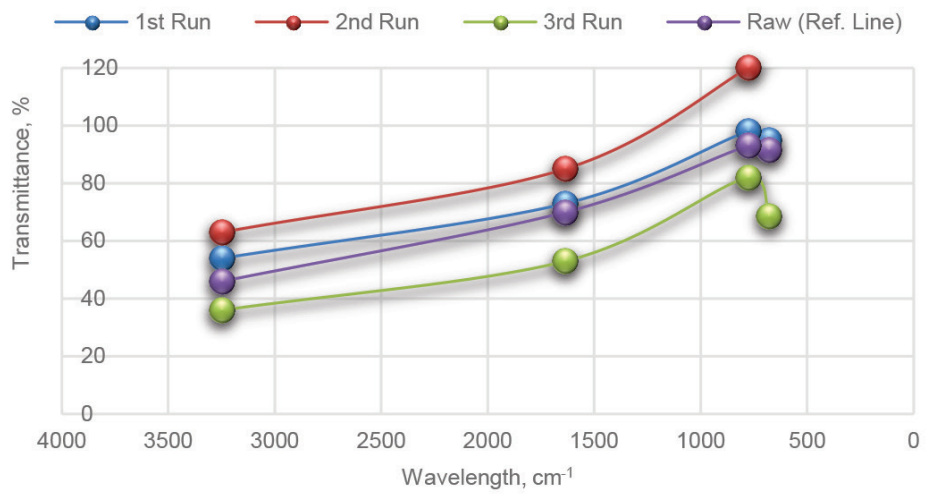

Figure 2: FTIR spectrum of feed solution.

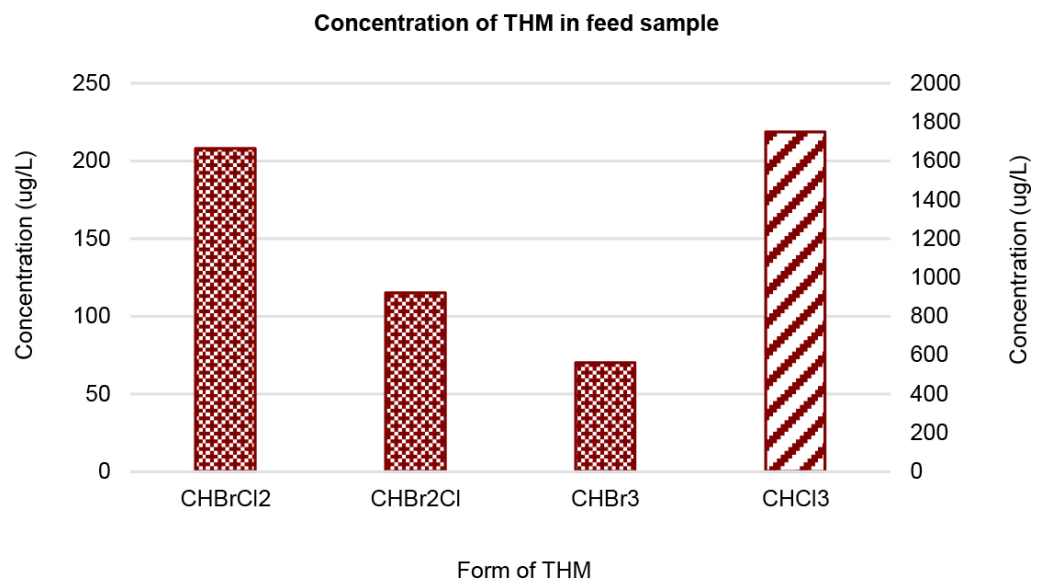

Figure 3: Concentration of THMs in feed solution. 


\subsection{Effect of $\mathrm{pH}$ on the THM Removal}

Figure 4 exhibits the effect of $\mathrm{pH}$ on the flux behaviour during ultrafiltration of THMs from petrochemical wastewater. It was noted that the greatest flux reduction occurred in an acidic level. Generally, the $\mathrm{pH}$ would affect the membrane surface charge and the solute charge. It was claimed by the researchers that a sieving mechanism is responsible for the retention of uncharged solutes, while for the charged components, an electrostatic interaction takes place between the components and the membrane. ${ }^{5}$

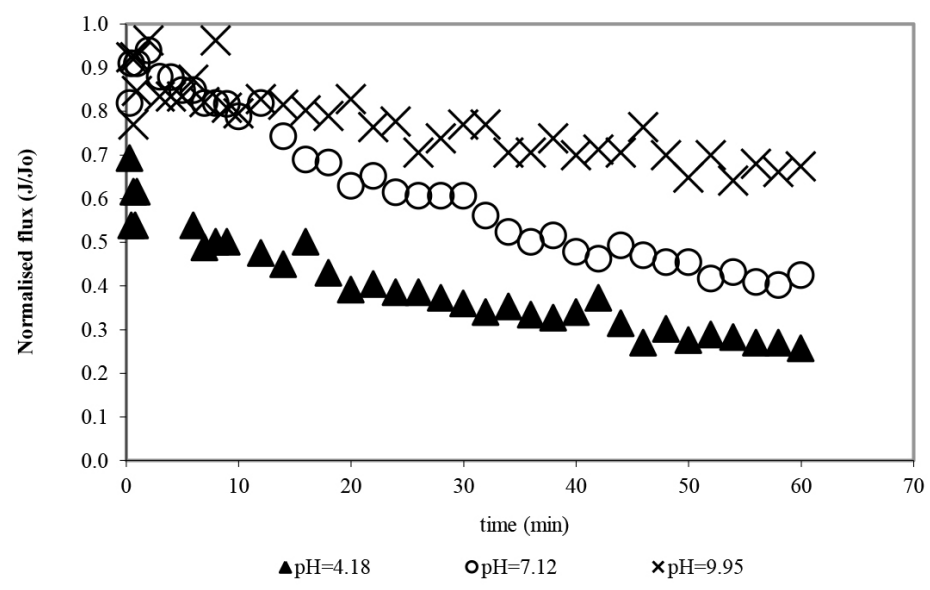

Figure 4: Effect of solution chemistry on flux decline of THMs.

Figure 5 represents the effect of $\mathrm{pH}$ to the THM removal. It was recorded that the concentration of bromodicholoromethane is significantly reduced to about $60.0 \%$ and $89.1 \%$ in alkaline and acidic conditions, respectively. For dibromocholoromethane, the concentration is reduced to about $43.48 \%$ at low $\mathrm{pH}$ and none was detected at high $\mathrm{pH}$. For chloroform, the concentration is only reduced to $8.23 \%$ at $\mathrm{pH} 10$ and can reach up to $69.00 \%$ at $\mathrm{pH} 4$. Essentially, the trend of THM removal is correlated with the flux performance as previously discussed.

The possible explanation for this condition is that an acidic solution carries a high concentration of hydrogen ion $\left[\mathrm{H}^{+}\right]$, in which acidic ions may act as proton donors. Therefore, reactions can occur with ion acceptors such as $\mathrm{OH}^{-}$to complete their chemical bonding of the compound to form other compound, thus increasing the molecular weight. Hence, it is difficult for the solute to pass through the membrane. On the other hand, metal salt is an ionic compound resulted from the neutralisation reaction of an acid and a base. The presence of metal salt is due to the addition 
of $\mathrm{NaOH}$ into the acidic sample which is regulated to increase the $\mathrm{pH}$. The acidic condition carries negatively charged ions due to salt-forming anions, oxide ions $\left(\mathrm{O}_{2}^{-}\right)$, which are negatively charged ions in the acidic solutions. High concentration of negative charge is due to $\mathrm{O}_{2}^{-}$ions. On top of that, the hydrophobicity of the PES membrane is negatively charged, hence there is a correlation between the membrane surface and the acidic solution. Due to negatively charged membrane and incomplete dissociation of THMs, the THMs would undergo higher removal in acidic level.

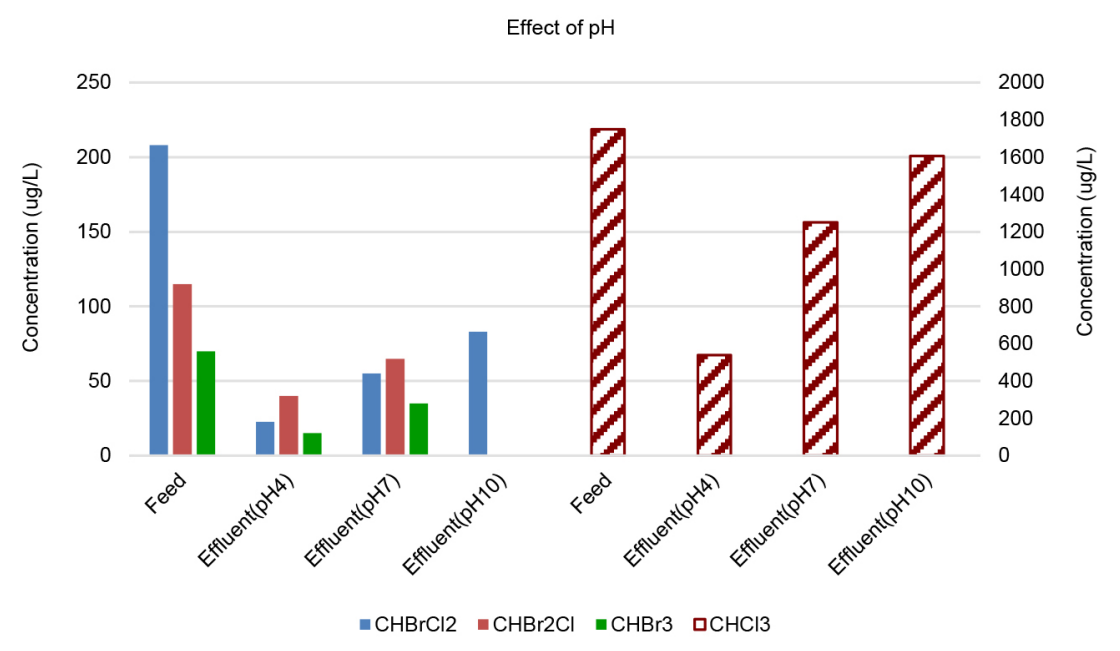

Figure 5: Effect of solution chemistry to the THM removal.

Figure 6 shows the determination of THMs at different $\mathrm{pH}$ values after ultrafiltration process. At low $\mathrm{pH}$, the functional group of THMs was identified at $717.22 \mathrm{~cm}^{-1}$. At neutral conditions, none of THM functional groups could be identified but there are still other regional peaks of other compounds. By comparing the result at $\mathrm{pH} 10$, it is clear that less or none of the compound in finger print area could be identified. 


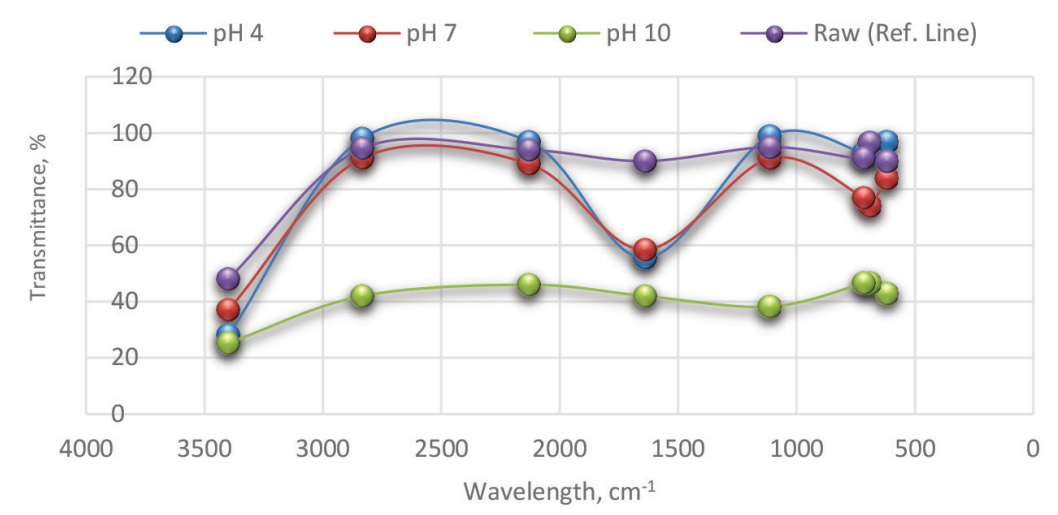

Figure 6: Effect of $\mathrm{pH}$ on the determination of THMs in wastewater sample.

\section{CONCLUSION}

Ultrafiltration process can be one of the promising technologies in removing THMs from wastewater. The characteristic of feed solution seems to play a major role in determining the permeate flux as well as flux reduction. The hydrophobicity behaviour of the membrane material and solution chemistry will influence the adhesion force between the solute and the membrane surface. The effective removal of THMs is expected occur at a low $\mathrm{pH}$ due to incomplete dissociation of the acid which carries a similar charge with membrane and induces repulsive force. A better filtration performance and insignificant removal of THMs was detected at high $\mathrm{pH}$ because of the lower reduction of concentration after the ultrafiltration. Even though there were THM reduction after treatment at both $\mathrm{pH}$, the content levels were considerably high compared to the regulated limit by the Malaysia's Ministry of Health. Hence, the application of membrane separation as a potential technology enables water treatment consultants, technologists and practitioners to determine the pre-treatment requirements without conducting time-consuming and costly pilot studies.

\section{ACKNOWLEDGEMENTS}

The authors wish to express their gratitude to the Petronas Penapisan (Melaka) Sdn. Bhd., Malaysia for supplying the samples for this study. The authors also gratefully acknowledge the financial support and the laboratory facilities provided by the Universiti Kuala Lumpur Malaysian Institute of Chemical and Bioengineering Technology (UniKL-MICET) for the analysis. The research is supported by the Short-term Research Grant (STRG) 17028. 


\section{REFERENCES}

1. New Hampshire Department of Environmental Services. (2006). Trihalomethanes: Health information summary. New Hampshire: New Hampshire Department of Environmental Services.

2. Cho, J., Amy, G. \& Pellegrino, J. (2000). Membrane filtration of natural organic matter: Factors and mechanisms affecting rejection and flux decline with charged ultrafiltration (UF) membrane. J. Membr. Sci., 164(1-2), 89110, https://doi.org/10.1016/S0376-7388(99)00176-3.

3. Madabhushi, B. S. (1999). What are trihalomethanes. Retrieved 16 December 2017 from http://www.nesc.wvu.edu/ndwc/articles/qanda/otsp99_q_a.pdf.

4. Silva-Medeiros, F. V. et al. (2012). Evaluation of the removal of chlorine, THM and natural organic matter from drinking water using microfiltration membranes and activated carbon in a gravitational system. InTech Open, 273-286, https://doi.org/10.5772/32395.

5. Waniek, A., Bodzek, M. \& Konieczny, K. (2002). Trihalomethane removal from water using membrane processes. Pol. J. Env. Stud., 11(2), 171-178.

6. Wenten, I. (2008). Ultrafiltration in water treatment and its evaluation as pretreatment for reverse osmosis. Unpublished paper, Bandung Institute of Technology, Indonesia.

7. Lin, Y. L., Chiang, P. C. \& Chang, E. E. (2006). Removal of small trihalomethane precursors from aqueous solution by nanofiltration. J. Hazard. Mater., 146(1-2), 20-29. 